\title{
THE UNSTEADY STATE OF THE ROSS ICE SHELF
}

\section{(Abstract only)}

\author{
by \\ Charles R. Bentley \\ (Geophysical and Polar Research Center, University of Wisconsin, Madison, \\ Wisconsin 53706, U.S.A.)
}

\begin{abstract}
According to our present picture, the Ross Ice Shelf is subject to relatively rapid changes, perhaps constantly out of steady state, but not undergoing a long-term secular change. Recent supporting evidence comes from a flow band of ice extending from the edges of Beardmore Glacier as far as Nimrod Glacier. The boundaries of that band and of ice steming from several individual glaciers within it have been traced on airborne radar records. Using measurements made as part of the Ross Ice Shelf Geophysical and Glaciological Survey (RIGGS) program, mass-flux variations along the bands have been calculated. The band from Nimrod Glacier, a major outlet glacier from the East Antarctic inland ice sheet, shows no significant
\end{abstract}

deviations from zero for the sum of the ice thickness change rate $\partial H / \partial t$ and bottom melt rate. $\dot{b}_{H}$. We interpret this to mean that $2 \mathrm{H} / \partial \mathrm{t}$ and $\dot{b}_{H}$ are separately small. Significant flux variations in the entire flow band are then attributed to relatively large variations in input flux from the alpine glaciers of the Transantarctic Mountains, and from zones between the glaciers. Although flux variations are not coherent between individual glacier bands, the average strengths of internal reflections (from bottom crevasses and/or included moraine), exhibit a semi-coherent variation with a period of 400 a that correlates with 180 variations in ice cores from Dome $C$ and Byrd station.

\section{SEISMIC INVESTIGATIONS OF THE FIRN-ICE STRUCTUREAT DOME C, EAST ANTARCTICA}

\author{
(Abstract only) \\ by \\ Donald D. Blankenship, Roger M. Gassett and Charles R. Bentley \\ (Geophysical and Polar Research Center, University of Wisconsin, Madison, \\ Wisconsin 53706, USA)
}

\section{ABSTRACT}

An extensive program of seismic refraction and reflection shooting was undertaken in the vicinity of Dome C station, East Antarctica (latitude $74^{\circ} 39^{\prime} \mathrm{S}$, longitude $\left.124^{\circ} 10^{\prime} \mathrm{E}\right)$. Refraction experiments (1978-79, 1979-80) were performed at 37 different shot-point-to-center-of-spread distances along four lines of different azimuth using receiver spacings of

2 to $30 \mathrm{~m}$. The principal result is an extremely wel1determined velocity-depth relation for the upper few hundred meters of the ice sheet. Availability of good bore-hole control at Dome $\mathrm{C}$ allows us to demonstrate the validity of Kohnen's (1972) density-velocity formula, which was developed for warmer ice. Also, after a careful search for azimuthal dependence of variations in the time-distance relationship along different refraction 1 ines, deviations from transverse isotropy in the firn and upper ice are not indicated. Our reflection work (1979-80), conducted along three mutually-centered lines $(10.2,10.2$, and
$10.7 \mathrm{~km}$ in length) oriented at $60^{\circ}$ angles to one another, used a series of 16 bore holes, each $30 \mathrm{~m}$ in depth, and 18 separate 24-channel recording stations. This extensive coverage combined with common reflection-point shooting geometries (to minimize topographic error) and small charge sizes (to increase resolution) yielded the highest quality set of reflection data yet obtained in East Antarctica. Significant crystalline anisotropy in the lower portion of the ice sheet is indicated. A model with 75\% of the ice thickness below the firn (approximately $2400 \mathrm{~m}$ ) having c-axes distributed throughout a vertical cone with a semi-apex angle of $20^{\circ}$ gives good agreement with the field observations.

\section{REFERENCE}

Kohnen H 1971 Über die Beziehung zwischen seismischen Geschwindigkeiten und der Dichte in Firn und Eis. Zeitschrift fur Geophysik $38(5)$ : 925-935 